\title{
DỨcin
}

Technological University Dublin ARROW@TU Dublin

2020-4

\section{Simulating Cement Hydration Using HYDCEM}

\author{
Niall Holmes \\ Technological University Dublin, niall.holmes@tudublin.ie \\ Denis Kelliher \\ University College Cork \\ Mark Tyrer \\ Coventry University
}

Follow this and additional works at: https://arrow.tudublin.ie/engschcivart

Part of the Construction Engineering and Management Commons

\section{Recommended Citation}

Holmes, N., Kelliher, D. \& Tyrer, M. (2020) Simulating Cement Hydration Using HYDCEM, Construction and Building Materials, Volume 239, 10 April 2020, 117811. DOI: 10.1016/j.conbuildmat.2019.117811

This Article is brought to you for free and open access by the School of Civil and Structural Engineering at ARROW@TU Dublin. It has been accepted for inclusion in Articles by an authorized administrator of ARROW@TU Dublin. For more information, please contact arrow.admin@tudublin.ie, aisling.coyne@tudublin.ie, gerard.connolly@tudublin.ie.

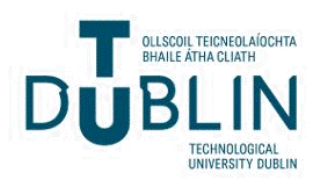




\section{Simulating cement hydration using HYDCEM}

Niall Holmes ${ }^{1, *}$, Denis Kelliher ${ }^{2} \&$ Mark Tyrer $^{3}$

${ }^{1}$ School of Civil \& Structural Engineering, Technological University Dublin, Dublin 1, Ireland

${ }^{2}$ School of Civil, Structural and Environmental Engineering, University College Cork, Cork. Ireland

${ }^{3}$ Centre for Research in the Built and Natural Environment, Coventry University, UK

Phone: +35314024039

Email: niall.holmes@tudublin.ie

*Corresponding Author

Abstract

HYDCEM is a new cement hydration model to simulate volumetric changes and predict phase assemblage, degree of hydration, heat release, compressive strength and chemical shrinkage over time for $\mathrm{PC}$ and limestone binders undergoing hydration for any $\mathrm{w} / \mathrm{c}$ ratio and curing temperatures between 5 to $45^{\circ} \mathrm{C}$. While models should never completely remove experimental analysis, they are an aid to better understand cement hydration and microstructure development by allowing users analyse different binders in a relatively short time. HYDCEM, written in MATLAB $®$, is aimed at complementing more sophisticated thermodynamic models giving users a reasonable prediction of hydration behaviour over time, using user-customisable inputs. A number of functions based on up to date cement hydration behaviour from the literature are included along with user-changeable inputs such as the cement chemical (oxide) composition, cement phase densities, species molar mass, phase and product densities and heat of hydration enthalpies. HYDCEM uses this input to predict the cement phase and gypsum proportions, volume stoichiometries and growth of hydration products including $\mathrm{C}-\mathrm{S}-\mathrm{H}$, calcium hydroxide, hydrogarnet (if applicable), hydrotalcite, ettringite, monosulphate, hemicarbonate and monocarbonate if limestone is present. A number of comparisons with published experimental and thermodynamic model results and HYDCEM predictions are provided to demonstrate its accuracy and usefulness. Previous work has shown that HYDCEM can reasonably accurately predict phase assemblages in terms of volume change and behaviour for a range of cements and curing temperatures. 


\section{INTRODUCTION}

2 Computer simulations are useful for cement scientists to observe hydration behaviour over time. This

3 includes the dissolution of cement and gypsum and the growth of hydration products over time. While

4 cement hydration and microstructure development is a very complex process, the advances in

5 computing power have made these simulations possible. During hydration, the volume of cement and

6 hydrates decrease and increase respectively over time and continues to do so as long as water and space

7 are available. There is also an increase in pore space due to chemical shrinkage. HYDCEM simulates

8 these changes in cement/binder, hydrates, water and chemical shrinkage over time using volume

9 stoichiometries based on established material properties available in the literature.

10 Cement consists of four main phases, namely tri-calcium silicate $\left(3 \mathrm{CaO} \cdot \mathrm{SiO}_{2}, \mathrm{C}_{3} \mathrm{~S}\right)^{1}$, di-calcium silicate $\left(2 \mathrm{CaO} \cdot \mathrm{SiO}_{2}, \mathrm{C}_{2} \mathrm{~S}\right)$, tri-calcium aluminate $\left(3 \mathrm{CaO} \cdot \mathrm{Al}_{2} \mathrm{O}_{3}, \mathrm{C}_{3} \mathrm{~A}\right)$ and tetra-calcium aluminate ferrite $\left(4 \mathrm{CaO} \cdot \mathrm{Al}_{2} \mathrm{O}_{3} \cdot \mathrm{Fe}_{2} \mathrm{O}_{3}, \mathrm{C}_{4} \mathrm{AF}\right)$. To perform accurate hydration simulations, it is important that the contribution from each phase is included to help identify the behaviour of existing and new cementitious materials.

HYDCEM, written in MATLAB ${ }^{\circledR}$, determines the change in cement/binder, gypsum, magnesium and subsequent hydration products over time using built in MATLAB ${ }^{\circledR}$ functions [1-3]. HYDCEM uses a fully user-customisable MS Excel input data file to read in information on the cement being analysed including oxide composition and predicts, using modified Bogue equations, the phase proportions. It also calculates the volume stoichiometries using well-established reaction molar masses in the literature. The model employs the empirical Parrot and Killoh method [4] to determine individual phase degree of hydration and uses this along with volume stoichiometries to determine the volumetric changes of the cement and of the hydration products over an user-defined time period (in hourly steps).

Over the years, a number of hydration and microstructure models have been developed that employed either the discretization, vector or cellular-automata approach using circles, spheres or discretized elements to represent cement particles. The Jennings and Johnson model [5,6] used spherical particles within a cubic volume where the reducing diameter of $\mathrm{C}_{3} \mathrm{~S}$ was predicted and increasing inner and outer $\mathrm{C}-\mathrm{S}-\mathrm{H}$ as hydration products formed over time. The model also determined the number of $\mathrm{CH}$ particles over time and placed them in the pore space. In the 1990's, an integrated particle kinetics model was developed by Navi and Pignat [7-10] who simulated the hydration of spherical $\mathrm{C}_{3} \mathrm{~S}$ particles using a similar vector approach as the Jennings and Johnson model $[5,6]$. This model used kinetic laws and relationships that simulated the hydration of every particle. The HYdration, MOrphology, and STRUCtural (HYMOSTRUC) model was developed by van Breugel [11] and simulates the 3D hydration of spherical particles. Reacting particles form concentric hydrating layers around the original cement grains, which grow and interact with each other. HYMOSTRUC employs various mass and volume balance rules to accommodate microstructural changes from the CEMENT dissolution and precipitation of various phases. The HydratiCA model was developed by Bullard at NIST [12] and is based on more fundamental principles of hydration kinetics. HydratiCA makes more detailed predictions of the kinetics of phase changes and microstructure development as a function of solution chemistry and temperature than other microstructure-based models of hydration.

The $\mu$ ic (pronounced "mike") microstructural modelling platform [13] has been written using objectoriented programming in Java and simulates the growth of millions of spherical particles representing real particle shape distributions (PSD's) to mimic hydration. The main advantage of $\mu$ ic is the fully user customizable nature of the simulations. Finally, probably the most well-known model CEMHYD3D [14], employs the discrete or pixel approach and the cellular-automata (CA) method where the microstructure is represented as a grid of discrete three-dimensional cubic elements, called volumepixels, or 'voxels' each representing an anhydrous or hydrate phase or pore.

\footnotetext{
${ }^{1}$ Conventional cement chemistry notation: $\mathrm{C}=\mathrm{CaO}, \mathrm{S}=\mathrm{SiO}_{2}, \mathrm{~A}=\mathrm{Al}_{2} \mathrm{O}_{3}, \mathrm{~F}=\mathrm{Fe}_{2} \mathrm{O}_{3}$, and $\mathrm{H}=\mathrm{H}_{2} \mathrm{O}$.
} 
To date, the development of cement hydration and microstructure models have used either the discretization or the vector approach with [15] providing a comprehensive review. This paper describes the design of HYDCEM along with examples of the customisable input files and examples of typical outputs.

\section{HYDCEM MODEL}

\section{Model design}

7 HYDCEM was developed to be as user-friendly as possible for engineers and scientists alike with a 8 vast amount of online documentation and help available for MATLAB ${ }^{\circledR}$ programmers making it 9 relatively easy to learn. It is programmed in $\operatorname{MATLAB}^{\circledR}[16]$, which is dedicated to undertaking multiple programming as it expresses inputs and results in matrix and vector format. By using multiple functions called from a main script, it allows the user to create a code with is easy to read and edit. While other programming languages may yield faster calculations, HYDCEM is capable of simulating 1,000 days of hydration $(24,000 \mathrm{hrs})$ in a couple of seconds.

Hydration of cement is dependent on the changes in solid volume as the hydration products continue to fill space over time. Before hydration begins, there is more cement than water, when expressed by weight (the w/c ratio). However, by volume, there is more water than cement as shown in Figure 1, for a w/c ratio of 0.4 and an average cement density of $3.3 \mathrm{~g} / \mathrm{cm}^{3}$. However, as hydration continues, the volume of water and cement decreases with a corresponding increase in hydration products and chemical shrinkage, as predicted by [17]. Using estimates of the change in volumetric phase fractions as a function of hydration [18], Figure 2 shows the change in volume as calculated in HYDCEM as described above. These volume changes give the cement its physical properties including strength. HYDCEM predicts these changes in volume for the cement, gypsum, hydration products, chemical shrinkage and water over time.

Data input for HYDCEM is provided within an MS Excel spreadsheet (input.xlsx) with the different inputs (in numerical format) contained in individual tabs. A description of the input is provided alongside the numerical data, to aid the users understanding. The input data required by HYDCEM include the $\mathrm{w} / \mathrm{c}$ ratio, phase heat release enthalpies, cement and hydration product densities, molar mass, molar reaction ratio, curing temperature and anhydrous cement oxide proportions. A suite of constants (also fully customisable) are required to simulate the dissolution of the four cement phases [4].

The analysis/calculation flow for HYDCEM is shown in Figure 3. As may be seen, when the input data files are read into the model, the analysis follows a well-structured methodology by using multiple functions within the main HYDCEM script along with pre-allocation of single precision outputs for quicker analysis. As shown, the sequence of calculation begins with determining the chemical properties including phase proportions, volume stoichiometries and molar masses of the oxides and products. This information is used to determine the volumes of the cement and gypsum as well as predicting the individual and overall degree of hydration of the phases and system respectively. The changing phases and gypsum volumes are used to determine the hydration products using four separate functions. Next, the heat of hydration, mortar strength and chemical shrinkage are calculated and finally, the various graphical outputs are produced to visualise how hydration and microstructure development is progressing.

The data is stored within predefined single column vectors with the number of rows equal to the number of hourly time steps. There is an expected increase in analysis time with the duration of hydration. However, for 24,000 hourly time steps (=1,000 days) are analysed in just over one second using an Intel ${ }^{\circledR}$ Core i7-8700 CPU desktop PC with $16 \mathrm{~Gb}$ of RAM.

\section{Analysis flow}

\section{Phase proportions}

Modified Bogue equations [19] are employed to predict the four phases and gypsum proportions within a function (bogue.m) using the oxide proportions. Modified Bogue equations have been found to yield 
higher $\mathrm{C}_{3} \mathrm{~S}$ and lower $\mathrm{C}_{2} \mathrm{~S}$ proportions than the standard method and provide better agreement with $\mathrm{SEM} / \mathrm{X}$-ray analysis [19]. $\mathrm{C}_{3} \mathrm{~A}$ or $\mathrm{C}_{4} \mathrm{AF}$ proportions did not give as good agreement but this may be due to the difficulty in distinguishing between these phases experimentally. However, as the modified Bogue equations give the best prediction of $\mathrm{C}_{3} \mathrm{~S}$ content, and due to its influence on cement hydration, this method is used in HYDCEM. The breakdown of oxides compositions and phase proportions using the modified Bogue method for the two cements as determined by HYDCEM are described in Table 1 $[20]$.

$8 \quad$ Volume stoichiometries

9 The changing volumes of the hydration products are calculated from the molar mass and density of each reactant (clinker) phase and the stoichiometry of the hydration reactions, that are also user customisable. Hydration of the calcium silicates dominate the system, forming portlandite and C-S-H. The reactions of $\mathrm{C}_{3} \mathrm{~A}$ and $\mathrm{C}_{4} \mathrm{AF}$ are dependent on the availability of sulphate ions from gypsum and ettringite $[21,22]$ and are coded into the model using a series of MATLAB ${ }^{\circledR}$ conditional statements. If gypsum is present, Equations (4) and (7) apply; if gypsum is consumed and ettringite is present, Equations (5) and (8) apply; finally, if both gypsum and ettringite are used up, Equations (3) and (6) apply. To aid readability, four separate MATLAB ${ }^{\circledR}$ functions for the silicates (volume_stoichiometry_silicates.m), aluminates (volume_stoichiometry_aluminates.m), ferrites (volume_stoichiometry_ferrite), and magnesium (volume_stoichiometry_magnesium.m) are called from the main script for (a) the silicates (Equations (1) \& (2)), (b) aluminates (Equations (3)-(5)), (c) ferrites (Equations (6)-(8)) and (d) magnesium (Equation (9)).

The molar mass reaction for the magnesium phase and hemicarbonate [23a \& 23b] products are shown in Equations (9) and (10) with their calculated volume stoichiometries in brackets below. The volume stoichiometries used by [14] in the CEMHYD3D model are shown in square brackets below for comparison. As may be seen, there are close agreements throughout.

$$
\begin{aligned}
& 1.0 \mathrm{C}_{3} \mathrm{~S}+5.3 \mathrm{H} \rightarrow 1.0 \mathrm{CSH}+1.3 \mathrm{CH} \\
& \text { (1.0) (1.3173) (1.5692) (0.5933) } \\
& \text { [1.0] [1.34] [1.521] [0.61] } \\
& 1.0 C_{3} A+6.0 H \rightarrow 1.0 C_{3} A H_{6} \\
& \begin{array}{lll}
(1.00) & (1.212) & (1.6834)
\end{array} \\
& \text { [1.0] [1.21] [1.69] } \\
& 2.0 C_{3} A+1.0 C_{6} A \$_{3} H_{32}+4 H \rightarrow 3.0 C_{4} A \$ H_{12} \\
& \text { (1.00) (3.9536) (0.4041) (5.2358) } \\
& {[1.00] \quad[4.125] \quad[0.404] \quad[5.272]} \\
& \text { (1) } 1.0 \mathrm{C}_{2} \mathrm{~S}+4.3 \mathrm{H} \rightarrow 1.0 \mathrm{CSH}+0.3 \mathrm{CH} \\
& {[1.0] \quad[1.49] \quad[2.077] \quad[0.19]} \\
& \text { (1.00) (2.0687) (5.2527) (7.9073) } \\
& \text { (5) } 1.0 \mathrm{C}_{4} \mathrm{AF}+10 \mathrm{H} \rightarrow 1.0 \mathrm{C}_{3} \mathrm{AH}_{6}+1.0 \mathrm{CH}+1.0 \mathrm{FH}_{3} \text { (6) } \\
& {\left[\begin{array}{lllll}
1.0] & {[1.41]} & {[1.17]} & {[0.26]} & {[0.545]}
\end{array}\right.}
\end{aligned}
$$$$
(1.00)(1.4752)(2.166)(0.189)
$$$$
\text { (3) } 1.0 \mathrm{C}_{3} \mathrm{~A}+3.0 \mathrm{C} \$ \mathrm{H}_{2}+26 \mathrm{H} \rightarrow 1.0 \mathrm{C}_{6} A \$_{3} \mathrm{H}_{32}
$$$$
[1.00] \quad[2.50] \quad[5.25] \quad[8.25]
$$$$
\begin{array}{llll}
(1.00) \quad(1.3828) & (1.1522) & (0.2539)(0.5468)
\end{array}
$$

25
HYDCEM can also include the addition of limestone in its hydration simulations using the molar mass reaction for limestone [24] in Equation (11). The calculated volume stoichiometries (volume_stoichiometry_limestone.m) shown in brackets below: 
$\begin{array}{llll}3.0 C_{4} A \$ H_{12} & +2.0 C_{a} \mathrm{CO}_{3}+18 H \rightarrow & 1.0 C_{6} A \$_{3} H_{32} & +2.0 C_{4} A C H_{11} \\ (1.00) & (0.079) & (0.347) & (0.757)\end{array}$

26 percentage, the binder $\mathrm{CaO}$ is $64.5 \%$.

\section{Cement volume and weights} changeable by the user, the default is 24,000 hours or 1,000 days.

\section{Cement phase dissolution calculations} influence of $\mathrm{w} / \mathrm{c}\left(=\left(1+3.333\left(\mathrm{H}^{*} \mathrm{w} / \mathrm{c}-\alpha_{\mathrm{t}}\right)\right)^{4}\right.$; for $\alpha_{\mathrm{t}}>\mathrm{H}^{*} \mathrm{w} / \mathrm{c}$.

$$
\begin{aligned}
& R_{t}=\frac{K}{N}\left(1-\alpha_{t}\right)\left(-\ln \left(1-\alpha_{t}\right)\right)^{(1-N)} \\
& R_{t}=\frac{K\left(1-\alpha_{t}\right)^{\frac{2}{3}}}{1-\left(1-\alpha_{t}\right)^{\frac{1}{3}}} \\
& R_{t}=K\left(1-\alpha_{t}\right)^{N}
\end{aligned}
$$
method.

The addition of limestone is included using a separate tab within the main input file where the user can specify the oxide proportions. The binder oxide proportions when limestone is added are determined by the relative phase proportions and calculated within the main input file. For example, if the plain cement and limestone has a $\mathrm{CaO}$ oxide proportion of $65 \%$ and $55 \%$ respectively, coupled with a $5 \%$ limestone

The volumes and weights of the four cement clinker phases, gypsum and magnesium are determined by two separate functions (volume_calculations.m \& phase_volumes.m). In HYDCEM, hydration calculations are undertaken in one-hour time steps. While the duration of hydration is completely

The dissolution of the four cement clinker phases in HYDCEM is simulated (phase_dissolution.m) using the approach presented by Parrot and Killoh [4] that uses a suite of empirical expressions to estimate the degree of hydration of each phase as a function of time. These calculations are in-built into HYDCEM with all constants $(\mathrm{K}, \mathrm{N}, \mathrm{H})$ and properties (activation energies, Blaine surface area, etc.) used for the Parrot and Killoh procedure [4] fully changeable by the user within the input.xlsx data file.

The dissolution of each clinker phase is determined using Equations (12)-(14) which represent nucleation and growth, diffusion and formation of a hydration shell respectively with the lowest hydration rate $R_{t}$ is taken as the rate-controlling value. The degree of hydration $(\alpha)$ is expressed as $\alpha_{t}=\alpha_{t}-1+\Delta_{t} \cdot R_{t-1}$. The K, N and $H$ values used for the three phases are those proposed by Lothenbach et al $[20,25]$. The influence of the surface area on the initial hydration are included, as well as the

Much has been written about the appropriateness of nucleation and growth, diffusion or the formation of a hydration shell to predict cement dissolution. Dissolution theory is providing theoretical and experimental evidence to suggest the most accurate way of describing the early dissolution of cement [26]. However, the Parrot and Killoh method [4] has also shown to give good comparisons with experimental results, despite being an empirical method. Until the dissolution theory is developed to a point where numerical prediction are possible, HYDCEM will continue to employ the Parrot and Killoh

The change in individual phase volume over time is determined using the product of the original phase volume and its corresponding degree of hydration. The changing phase weights (phase_weights.m) over time are also determined using the product of their individual degree of hydration and original weights. Figure 4 and Figure 5 show examples of the HYDCEM predicted degree of hydration (using Equations 12-14) and phase weight changes over time, using the PC cement properties shown in Table 1. 
1 HYDCEM allows the user to input curing temperatures from 5 to $45^{\circ} \mathrm{C}$. As shown by [25], up to 2 approximately $48^{\circ} \mathrm{C}$, all hydrates are stable. However, above $48^{\circ} \mathrm{C}$, ettringite becomes unstable (Figure

3 6) as the ions liberated into solution re-precipitate as monosulphate. Currently, HYDCEM limits the 4 temperature range as the conceptual model cannot account for the behaviour shown in Figure 6. The 5 practical applications that require such high curing temperatures $\left(>45^{\circ} \mathrm{C}\right)$ are mostly limited to the 6 precast concrete industry so this limitation may have minimal impact.

7 Lower curing temperatures produces a less dense C-S-H, a more even distribution of hydration products 8 and a less coarse porosity [27-31]. Higher temperatures cause an initially fast dissolution of the four 9 clinker phases and a more rapid precipitation of initial hydration products [27]. This leads to higher early strength development, along with a more heterogeneous distribution of hydration products in and around the clinker particles [29]. If the user does input a curing temperature lower than $5^{\circ} \mathrm{C}$ or higher than $45^{\circ} \mathrm{C}$, the model will automatically terminate.

\section{Hydration product volumes}

As hydration continues, the volume of solid products including $\mathrm{C}-\mathrm{S}-\mathrm{H}$, calcium hydroxide $(\mathrm{CH})$, ettringite, monosulphate, hydrotalcite, hydrogarnet, hemicarbonate and monocarbonate increases. These changes in volume are determined in HYDCEM by five separate functions for the silicates (phase_hydration_silicates.m), aluminates (phase_hydration_aluminates.m), ferrites (phase_hydration_ferrite.m), magnesium (phase_hydration_magnesium.m) and limestone (limestone_hydration.m) using the change in the four clinker phases and the stoichiometries shown (in brackets) in Equations (1)-(11). Figure 7 shows some examples of this approach used by other models $[13,7-9]$ with the reduction in $\mathrm{C}_{3} \mathrm{~S}$ alongside growth in inner and outer C-S-H and portlandite.

Figure 8 shows a phase assemblage plotted in HYDCEM with volumetric changes in the cement phases, gypsum and solid volume over 1,000 days (24,000 hours) at $20^{\circ} \mathrm{C}$ using the Portland cement described in Table 1. HYDCEM has implemented well accepted cement hydration behaviour for the aluminates phase found in the literature. For example, the growth in monosulfate (for limestone free cements) begins after approximately three days, well after the gypsum has been depleted. Also, the volume of ettringite is shown to increase until the gypsum is consumed but decreases over time as it is converted to monosulphate [20]. Figure 9shows a second HYDCEM phase assemblage for the limestone cement described in Table 1. As may be seen, the growth of monocarbonate and ettringite are shown to begin after the depletion of gypsum at one and three days respectively. It has been shown [25] that for limestone binders, monocarbonate forms in place of monosulfate from approximately one day and ettringite is stable. These behaviours have been experimentally measured and thermodynamically modelled for plain and limestone binders by [20] and summarised in Figure 10.

Figure 11 and Figure 12 shows the growth in silicates and aluminates hydration products respectively over time. Comparing the HYDCEM predictions of aluminate changes in Figure 12 with Figure 10, it is clear that the model is simulating the behaviours of plain and limestone cements reasonably well over time.

\section{Heat release and heat of hydration}

Using published [14] enthalpies for each of the four clinker phases (Table 2), HYDCEM predicts the heat release and heat of hydration over time. Using these phase enthalpies and previously calculated changes in phase weights at every time step, Figure 13 presents the predicted heat evolutions for the PC cement described in Table 1. Published isothermal calorimetry measurements [20] have indicated the onset of the acceleration period begins approximately 3 hours into hydration (Figure 14(a)), which has been coded into HYDCEM. Figure 13(a) shows that the maximum heat flow rate is predicted to occur after nine hours, which agrees with published experimental analysis [20] of these cements. However, while Figure 14(a) shows a slight increase in heat evolution for the limestone cements, this is not shown in the HYDCEM predictions. This is because the heat evolution is dependent on the initial phase $\left(\mathrm{C}_{3} \mathrm{~S}\right.$, $\mathrm{C}_{2} \mathrm{~S}$, etc.) proportions. As the main oxide contents for the limestone shown in Table 1are lower than the plain cement, the heat evolution is less. HYDCEM is currently unable to account for the acceleration in 
1 hydration and follow on heat evolution due to the presence of limestone which creates additional

2 surfaces for the nucleation and growth of hydration products [30,31].

\section{Chemical shrinkage}

4 Chemical shrinkage during hydration arises due to volume differences between the hydrating cement and solids precipitated and is commonly referred to as the Le Chatelier's contraction [32]. In Equation (1) for instance, the sum of the stoichiometric volumes on the left (2.34) and right (2.231) hand side leads to chemical shrinkage as the hydrated products are denser than the clinker minerals and water that formed them. HYDCEM can predict the chemical shrinkage over time for any cement. Figure 15 shows the predicted chemical shrinkage for the cement (solid line) and limestone binder (dashed line) as described in Table 1. As may be seen, the chemical shrinkage for the limestone binder is slightly less than the plain cement. This is contrary to [32] who found the presence of limestone increased chemical shrinkage due to the additional surface area. Figure 16 shows measured chemical shrinkage from [33] for various cements and w/c ratios with reasonably good agreement it and Figure 15.

\section{Estimation of mortar compressive strength}

Using Powers' gel-space ratio principal in Equation (15) [34-36] where $\mathrm{X}$ is the gel-space ratio and $\alpha$ is the overall degree of hydration, HYDCEM provides a prediction of the mortar compressive strength development over time. The $\alpha$ term in Equation 15 is calculated using Equation 16 where $\alpha^{\mathrm{p}}$ is the individual phase degree of hydration and prop ${ }^{\mathrm{p}}$ is the proportion $(\%)$ of $\mathrm{C}_{3} \mathrm{~S}, \mathrm{C}_{2} \mathrm{~S}$, etc.

Previous work by Bentz [34] has shown that the compressive strength of ASTM C109 mortar cubes [37] over time can be predicted using Equation 17, where $X$ is the gel-space ratio (Equation 14), $\sigma_{A}$ is the intrinsic strength of the cement and $n$ is a constant that, depending on the cement, ranges between 2.6 and 3.0. For $\mathrm{C}_{3} \mathrm{~A}$ Bogue contents below 7\%, the value of $\sigma_{A}$ should be lower [40]. Bentz [34] used intrinsic strength values of 129 and 99MPa for NIST Cements 115 and 116 respectively with a w/c ratio of 0.485 that provided good correlations between measured and predicted, as shown in Figure 17. The values for $\sigma_{A}$ and $n$ are provided in the input file and changeable by the user.

$$
\mathrm{X}=\frac{0.68 \alpha}{0.32 \alpha+w / c}
$$

$$
\alpha=\frac{\operatorname{prop}^{C 3 S} \alpha^{C 3 S}+\operatorname{prop}^{C 2 S} \alpha^{C 2 S}+\operatorname{prop}^{C 3 A} \alpha^{C 3 A}+\operatorname{prop}^{C 4 A F} \alpha^{C 4 A F}}{\operatorname{prop}^{C 3 S}+\operatorname{prop}^{C 2 S}+\operatorname{prop}^{C 3 A}+\operatorname{prop}^{C 4 A F}}
$$

$$
\sigma_{c}(\mathrm{t})=\sigma_{A} X(t)^{n}
$$

An example of the HYDCEM predicted compressive strengths using this approach with the plain Portland cement in Table 1 is shown in Figure 18. An intrinsic strength and ' $n$ ' value of 83.55MPa and 2.6 respectively were used. Work is underway to cast, measure and predict compressive strengths using ASTM C109 [37] mortar cubes where intrinsic strength and $n$ values can be developed for various w/c ratios and curing temperatures.

\section{DISCUSSION}

Modelling of cement and concrete poses many challenges and raises a number of questions. Is it desirable to seek an all-embracing model that simulates the chemistry and physics of these materials from emplacement in the fresh, unhydrated state, through many complex and competing chemical reactions to the conditions prevailing during hydration and normal service, ultimately to their end of their useful life? We suggest not, for two important reasons. The users of such a model are unlikely to require all the predictions such sophistication offers. Moreover, the demand for complex and comprehensive input data becomes restrictive and is likely to limit the value of such an approach. 
The method described here, takes well-established relationships between physical and chemical properties of hydrating cement and seeks, through its implementation on a widely-used modelling platform $\left(\mathrm{MATLAB}{ }^{\mathbb{R}}\right)$, to simulate the effects which dominate Portland cement hydration. The predictions include mass-balance of the phase assemblage, volumetric changes including chemical shrinkage, heat evolution and likely strength development as a function of hydration time. In doing so, some compromises have been necessary such as a somewhat modest representation of the chemical evolution, yet the method remains accessible, rapid and flexible. This model will be extended through adoption of more robust and exacting thermodynamic routines in due course, accounting for competition between hydration reactions and prediction of the pore solution evolution. However, the authors believe the current model will be of interest to the engineering community and provides an accessible means of predicting the hydration of Portland cement.

\section{CONCLUSIONS}

A new model, HYDCEM, has been presented that simulates the volume changes in cement phase and hydration products over time. The model, written in MATLAB ${ }^{\circledR}$, is capable of simulating over 1,000 days of hydration in a few seconds. It has been designed to be as user-friendly as possible with easy to read, understand and change input data via an EXCEL spreadsheet. HYDCEM incorporates established hydration behaviour in the literature by using MATLAB ${ }^{\circledR}$ statement operators. These have provided good predictions compared with published experimental results of phase dissolution, hydration product volume growth and heat release. Ongoing work to couple HYDCEM with the PHREEQC thermodynamic model will provide a long-term/equilibrated prediction of the pore water chemistry.

HYDCEM is intended to complement more sophisticated thermodynamic models to allow engineers and cement scientists assess existing and new cements using its chemical/oxide proportions, w/c ratio and curing temperature. Most data required by HYDCEM to run an analysis is available in the literature, for instance phase and product density, molar masses, enthalpies, molar ratio of reaction and parameters for the Parrot \& Killoh methodology to predict phase degree of hydration.

HYDCEM currently simulates the hydration of plain (PC) and limestone cements. Work is ongoing to model the effects of supplementary cementitious materials additions including GGBS and fly ash.

\section{ACKNOWLEDGEMENTS}

The authors gratefully acknowledge the assistance from Professor Barbara Lothenbach, Mr. Dale Bentz and Dr. Shashank Bishnoi who has been a great source of advice and assistance during HYDCEM's development.

\section{REFERENCES}

[1] Holmes, N., Griffin, A., Enright, B. \& Kelliher, D (2018) Introducing a new cement hydration and microstructure model, Civil Engineering Research in Ireland Conference, pp. 202-207, August, University College Dublin, Ireland.

[2] Holmes, N., Kelliher, D. \& Tyrer, M. (2019) HYDCEM: A new cement hydration model, ICSBM 2019 2nd International Conference of Sustainable Building Materials, pp. 66-74, 12-15 August, Eindhoven The Netherlands.

[3] Holmes, N., Kelliher, D. \& Tyrer, M. (2019) Modelling the addition of limestone in cement using HYDCEM, 39th Cement and Concrete Science Conference, pp. 23-27, 9-10th September 2019, University of Bath, UK.

[4] L.J. Parrot, D.C. Killoh, Prediction of cement hydration, Br. Ceram. Proc. 35 (1984) 41-53.

[5] H.M. Jennings, S.K. Johnson, Simulation of microstructure development during the hydration of a cement compound, Journal of the American Ceramic Society 69 (1986) 790-795. 
[6] S.K. Johnson, H.M. Jennings, Computer simulated hydration of a cement model, Proceedings of the 10th CIB congress, International Council for Building Research, Studies, and Documentation, Washington D.C., U.S.A., 1986, pp. 2086-2095.

[7] P. Navi, C. Pignat, Simulation of cement hydration and the connectivity of the capillary pore space, Advanced Cement Based Materials 4 (1996) 58-67.

[8] P. Navi, C. Pignat, Three-dimensional characterization of the pore structure of a simulated cement paste, Cement and Concrete Research 29 (1999) 507-514.

[9] P. Navi, C. Pignat, Effects of cement size distribution on capillary pore structure of the simulated cement paste, Computational Materials Science 16 (1999) 285-293.

[10] C. Pignat, P. Navi, K. Scrivener, Simulation of cement paste microstructure hydration, pore space characterization and permeability determination, Materials and Structures 38 (2005) 459-466.

[11] K. van Breugel, Numerical simulation of hydration and microstructural development in hardening cement-based materials (I): Theory, Cement and Concrete Research 25 (1995) 319-331.

[12] J.W. Bullard, A three-dimensional microstructural model of reactions and transport in aqueous mineral systems, Modell. Simul. Mater. Sci. Eng. 15 (2007) 711-738.

[13] Bishnoi, S and Scrivener, K.L (2009) $\mu$ ic: A new platform for modelling the hydration of cements, Cement and Concrete Research 39, pp. 266-274.

[14] Bentz D.P. CEMHYD3D: A three-dimensional cement hydration and microstructure development modelling package. Version 2.0. NISTIR 6485, US Department of Commerce, April 2000.

[15] J.J. Thomas, J.J. Biernacki, J.W. Bullard, S. Bishnoi, J.S. Dolado, G.W. Scherer, A. Luttge, Modeling and simulation of cement hydration kinetics and microstructure development, Cement and Concrete Research 41 (2011) 1257-1278

[16] Mathworks https://uk.mathworks.com/products/matlab.html

[17] Powers, T.C., and Brownyard, T.L., Studies of the Physical Properties of Hardened Portland Cement Paste, ACI Journal, Proceedings V. 43, Oct. 1946 to Apr. 1947 (published in multiple parts); also published as PCA Bulletin 22, Research Laboratories of the Portland Cement Association, Chicago, IL, 1948.

[18] Bentz DP, Irassar EF, Bucher BE, Weiss WJ. Limestone fillers conserve cement; Part 1: an analysis based on Powers' model. Concr Int. 2009;31:41-46.

[19] ASTM C150-09, standard specification for portland cement. Annual Book of ASTM Standards, ASTM International, West Conshocken, PA, 4.

[20] Lothenbach, B., Le Saout, G., Gallucci, E. and Scrivener, K. (2008) Influence of limestone on the hydration of Portland cements, Cement and Concrete Research 38 pp. 848-860.

[21] Bentz, D.P., Coveney, P.V., Garboczi, E.J., Kleyn, M.F. and Stutzman, P.E. (1994). Cellular automaton simulations of cement hydration and microstructure development. Modelling and Simulation in Materials Science and Engineering, 2(4), pp.783-808. 
[22] Merzouki, T., Bouasker, M., Khalifa, N.E.H. and Mounanga, P. (2013). Contribution to the modelling of hydration and chemical shrinkage of slag-blended cement at early age. Construction and Building Materials, 44, pp.368-380.

[23a] Brouwers, H. J. H. (2004). The work of Powers and Brownyard revisited: part 1. Cement and concrete research, 34(9), 1697-1716.

[23b] Brouwers, H. J. H. (2005). The work of Powers and Brownyard revisited: Part 2. Cement and concrete research, 35(2005), 1922-1936.

[24] Mohamed, A.R., Elsalamawy, M and Ragab, M (2015) Modelling the influence of limestone addition on cement hydration, Alexandria Engineering Journal 54, pp. 1-5.

[25] Lothenbach, B., Winnefeld, F., Alder, C., Wieland, E., and Lunk, P. (2007) Effect of temperature on the pore solution, microstructure and hydration products of Portland cement pastes, Cement and Concrete Research 37 (4) pp. 483-491.

[26] Juilland, P., Gallucci, E., Flatt, R and Scrivener, K (2010) Dissolution theory applied to the induction period in alite hydration, Cement and Concrete Research 40 831-844

[27] Lothenbach, B. Thermodynamic modelling of the effect of temperature on the hydration of Portland cement, International RILEM Symposium on Concrete Modelling - CONMOD 2008, 26-28 May, Delft, The Netherlands.

[28] Kjellsen, K.O., Detwiler, R.J, (1992) Reaction-kinetics of Portand-cement mortors hydrated at different temperatures, Cement \& Concrete Research 22 (1), pp. 112-120.

[29] Escalante-Garcia, J.I., Sharp, J.H. (1998) Effect of temperature on the hydration of the main clinker phases in Portland cements: Part I, neat cements, Cement \& Concrete Research 28 (9), pp. 1245-1257.

[30] Komonen, J., Penttala, V. (2003) Effects of high temperatures on the pore structure and strength of plain and polypropylene fiber reinforced cement pastes, Fire Technol 39 (1), pp. 23-34.

[31] Thomas, JJ., Rothstein, D., Jennings, H.M., Christensen, B.J. (2003), Effect of hydration temperatures on the solubility behaviour of Ca-, S-, Al- and Al- and Si- bearing solid phases in Portland cement pastes, Cement \& Concrete Research 33 (12), pp. 2037-2047.

[32] Bouasker, M., Mounanga, P., Turcry, P., Loukili, A. and Khelidj, A. (2008) Chemical shrinkage of cement pastes and mortars at very early age: Effect of limestone filler and granular inclusions, Cement and Concrete Composites, Vol. 30, pp. 13-22.

[33] Tongsheng Zhang, Peng Gao, Ruifeng Luo, Yiqun Guo, Jiangxiong Wei, Qijun Yu (2013) Measurement of chemical shrinkage of cement paste: Comparison study of ASTM C 1608 and an improved method, Construction and Building Materials 48, pp. 662-669

[34] Bentz, D.P., “A Three-Dimensional Cement Hydration and Microstructure Program. I. Hydration Rate, Heat of Hydration, and Chemical Shrinkage," NISTIR 5756, U.S. Department of Commerce, November 1995 (available from National Technical Information Service).

[35] Bentz, D.P., "Three-Dimensional Computer Simulation of Cement Hydration and Microstructure Development," J Amer Ceram Soc, Vol. 80 (1), 3-21 (1997). 
[36] Powers, T.C., "Physical Properties of Cement Paste," in Proceedings of the 4th International Symposium on the Chemistry of Cement, Washington, D.C., Vol. 2, Paper V-1, 577-613 (1962).

[37] Annual Book of ASTM Standards, Vol. 04.01. Cement; Lime; Gypsum (ASTM, Philadelphia, PA, 1992). 


\section{LIST OF FIGURES}

2
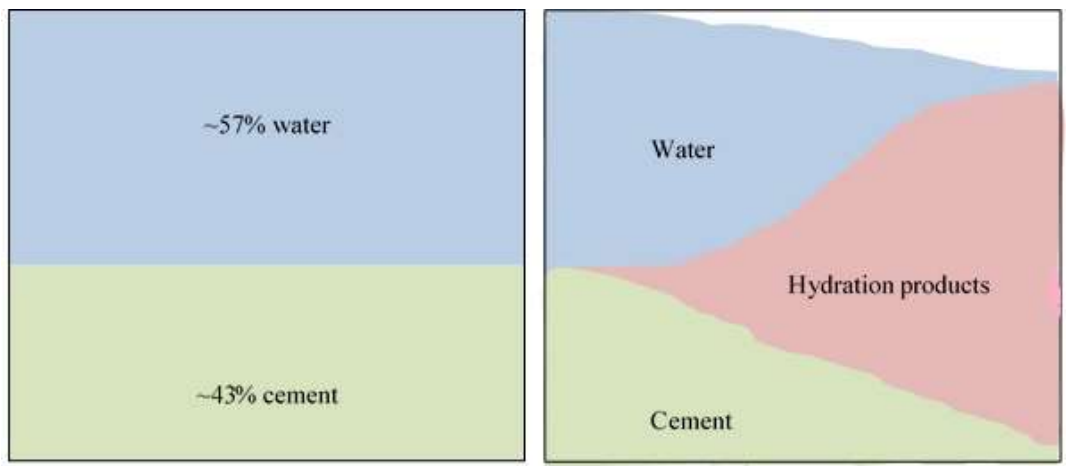

4 Figure 1: Changes in hydration volume over time within a defined volume 5

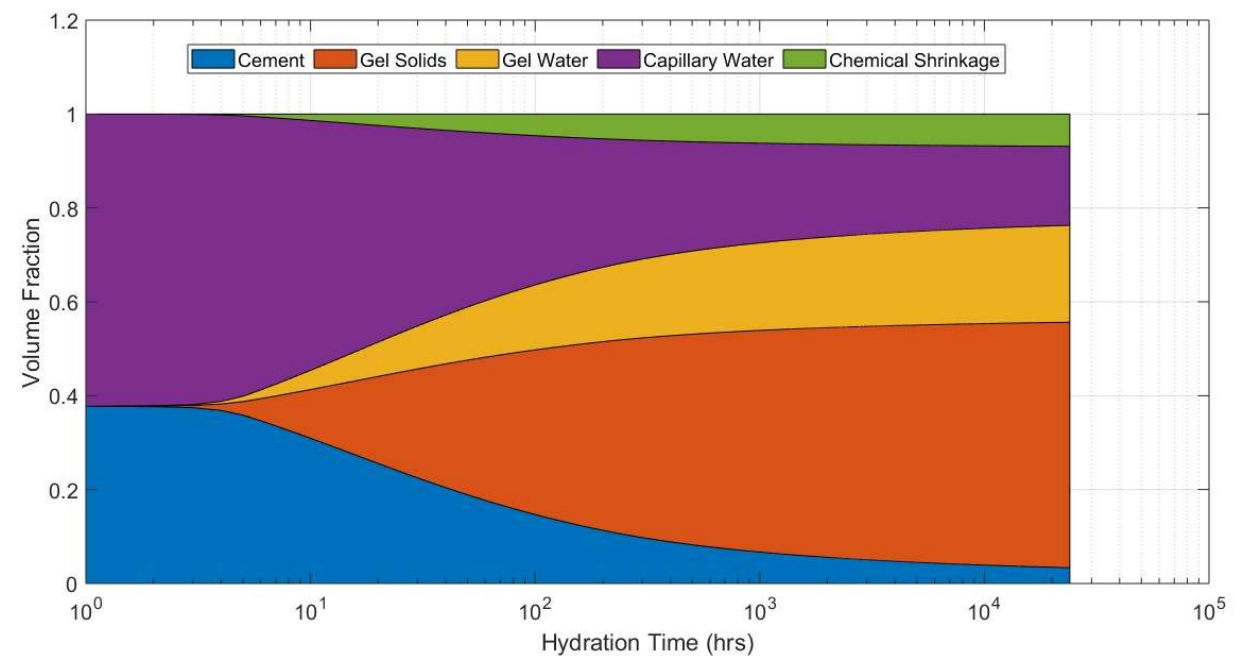

7 Figure 2: Change in volume with ongoing hydration as predicted by [17].

8

9 


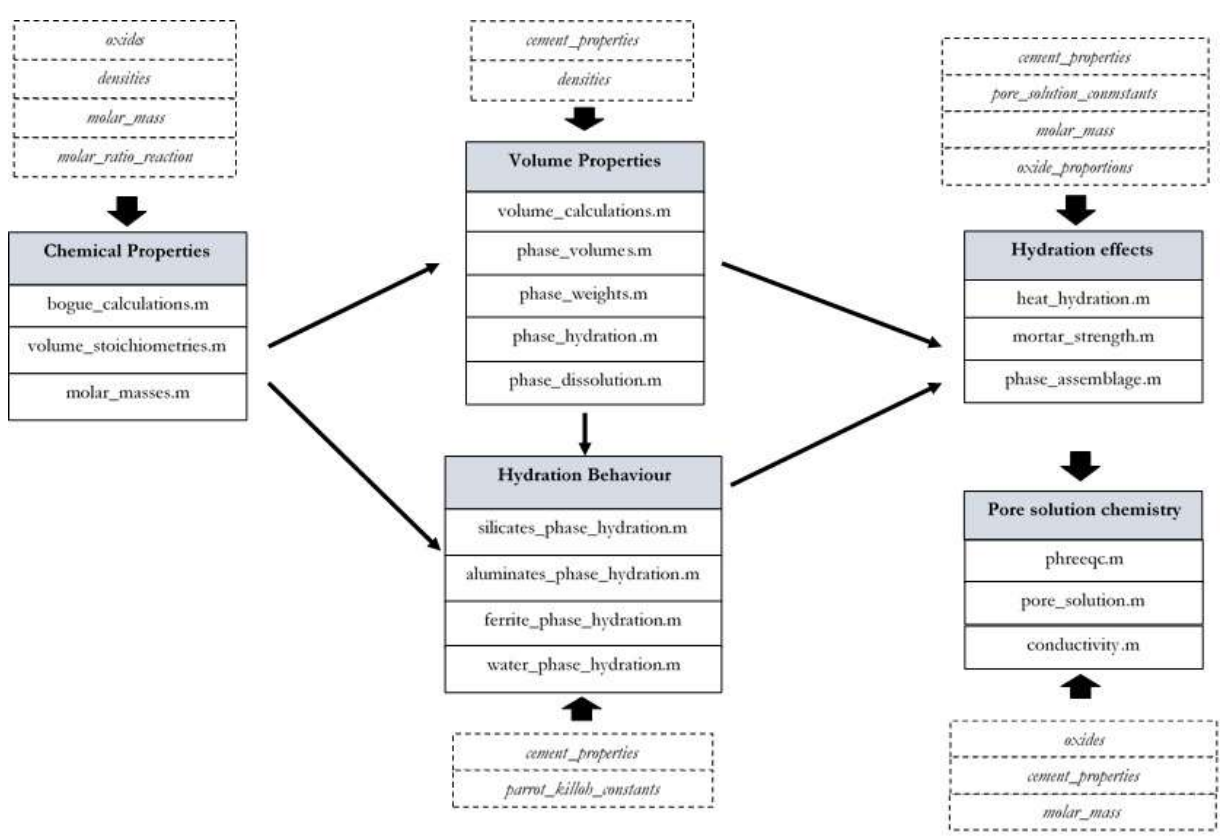

2 Figure 3: HYDCEM structure

3

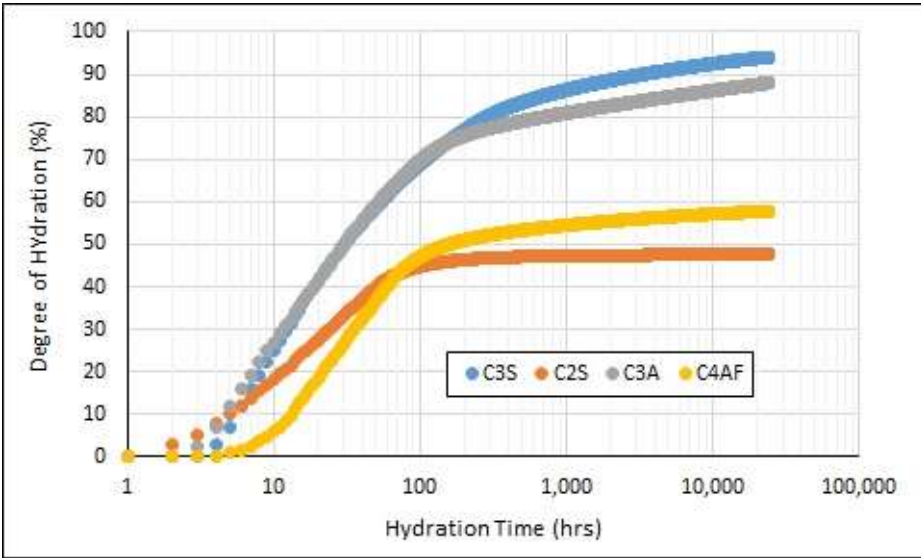

5 Figure 4: HYDCEM degree of hydration output

6 


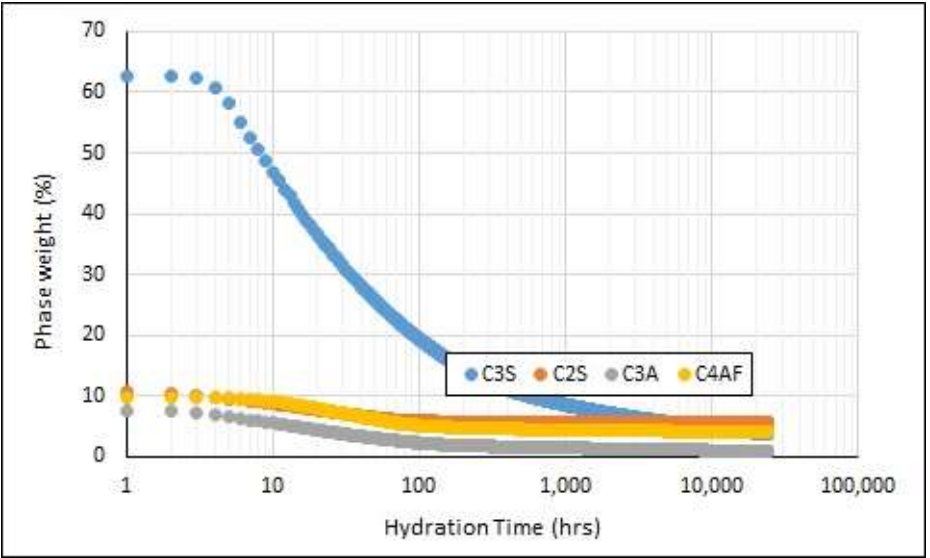

2 Figure 5: HYDCEM change in phase weight output

3

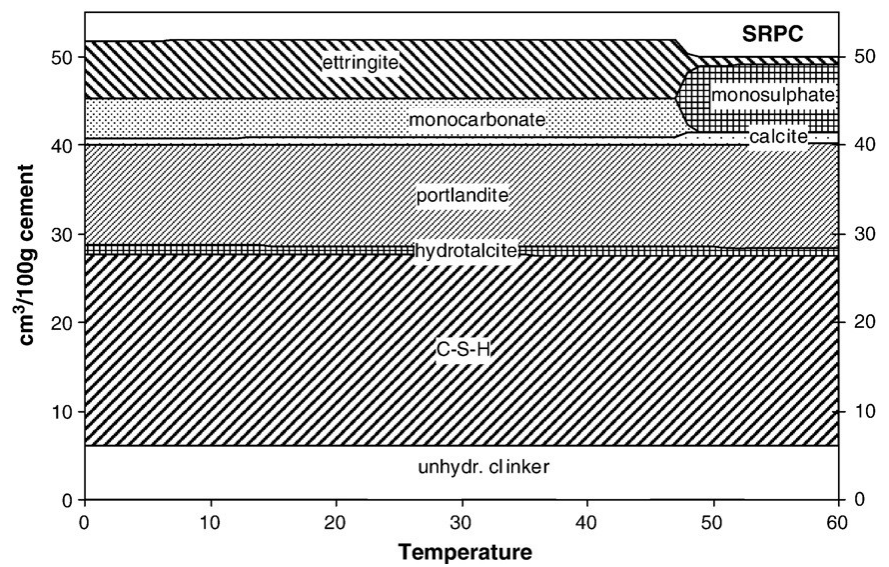

$5 \quad$ Figure 6: Effect of higher temperatures on hydrates [25]

6
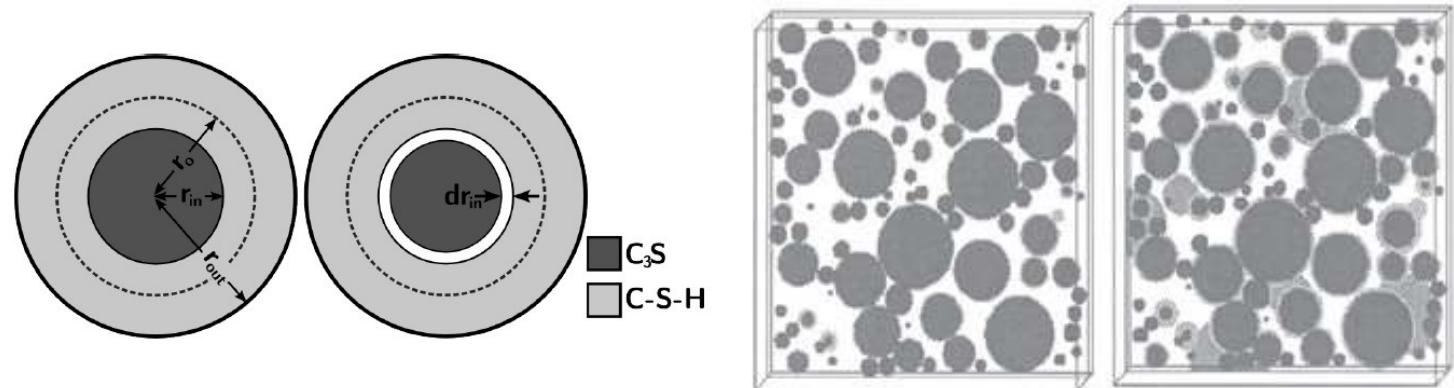

7 Figure 7: Increase in hydration product volume with decreasing cement phase [13,7-9] 8 


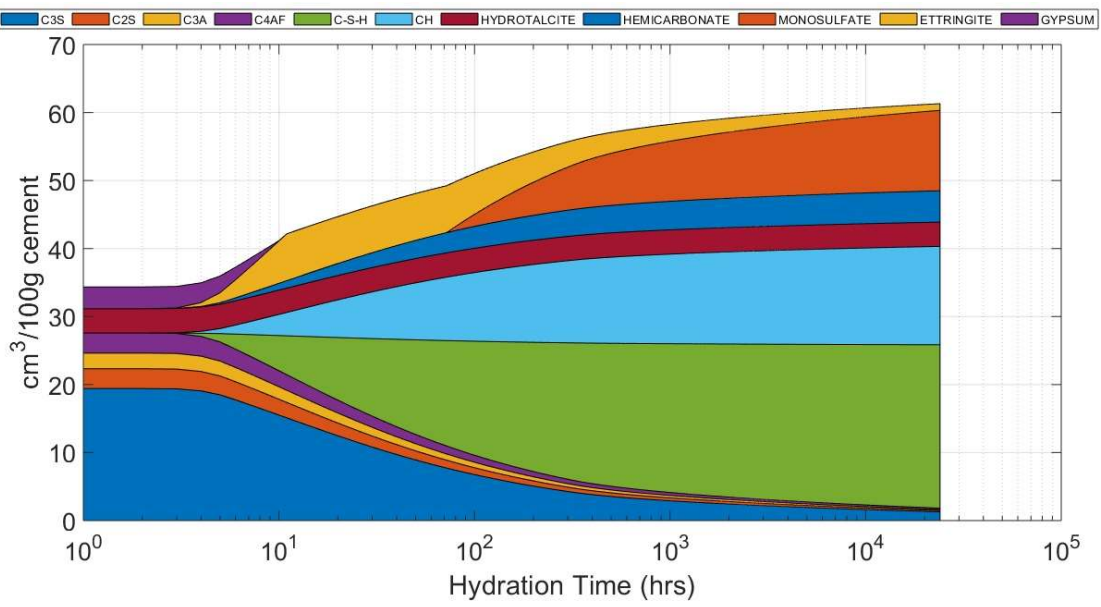

2 Figure 8: HYDCEM Phase assemblage - PC cement

3



4

5 Figure 9: HYDCEM Phase assemblage - Limestone cement

6

7

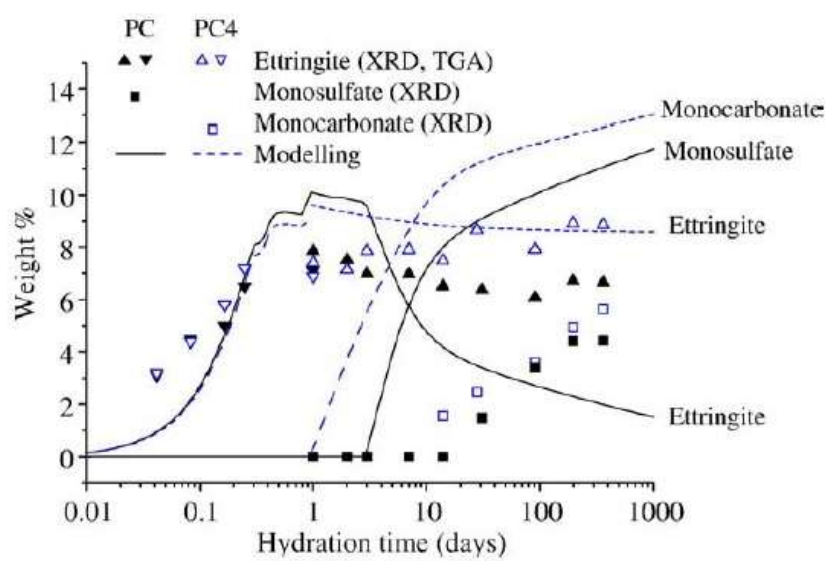

Figure 10: Results from experimentally measured and thermodynamic modelled changes during the 10 hydration of a Portland cement with and without limestone [20] 




2 Figure 11: Silicates products of hydration with (dashed) and without (solid) limestone.

3

4

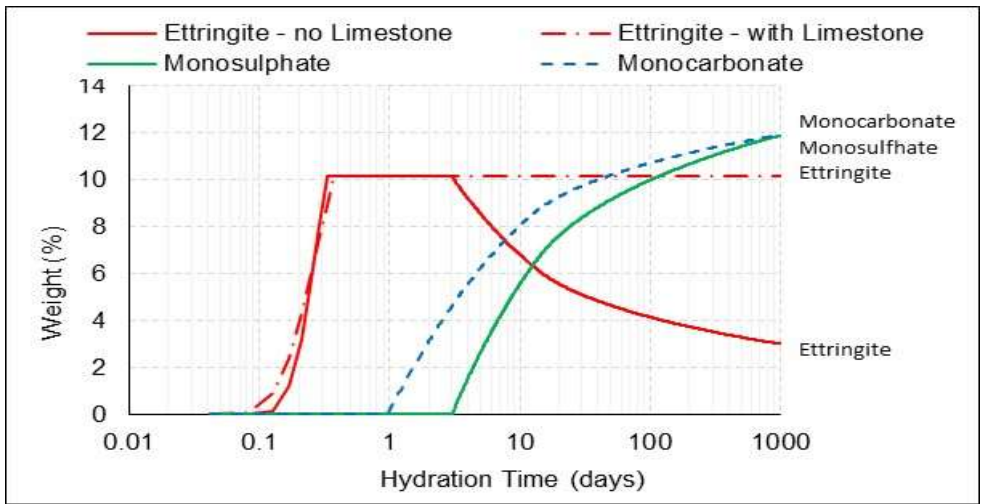

$5 \quad$ Figure 12: Aluminates products of hydration with (dashed) and without (solid) limestone.

6

7

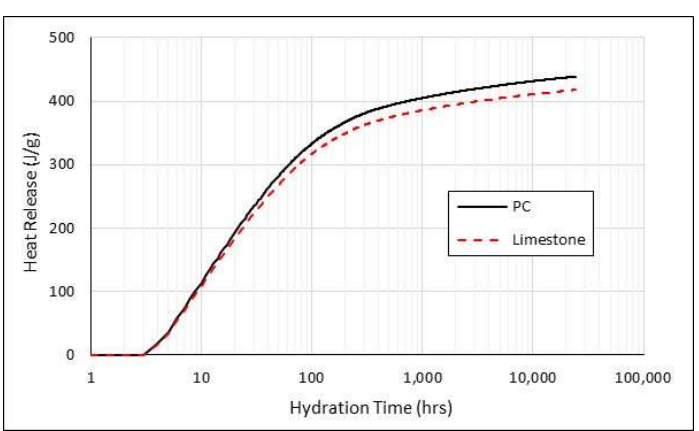

(a)

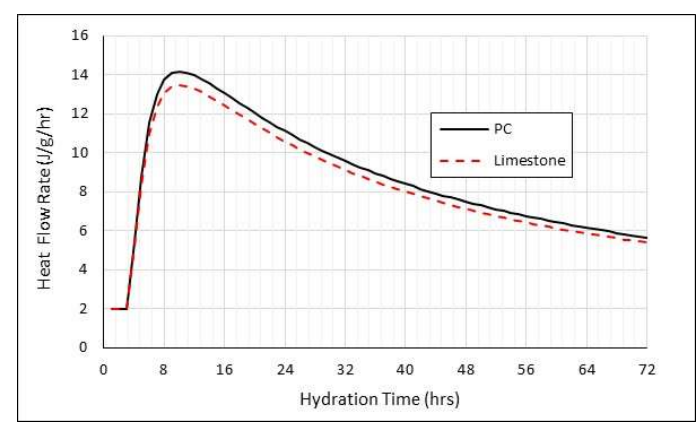

(b)

8 Figure 13: (a) Heat release and (b) heat flow rate prediction for PC (solid line) and limestone binder

9 (dashed line) over time 


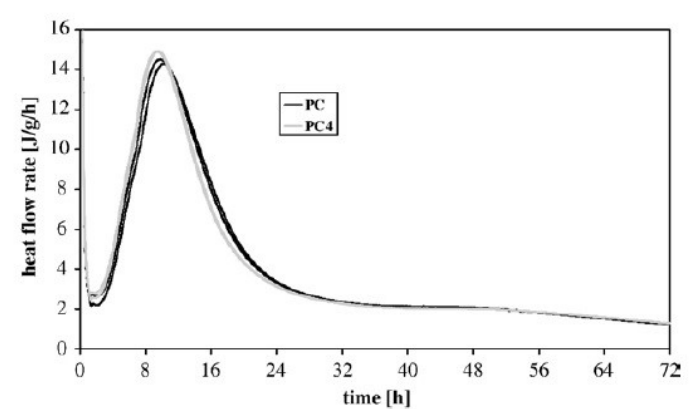

(a)
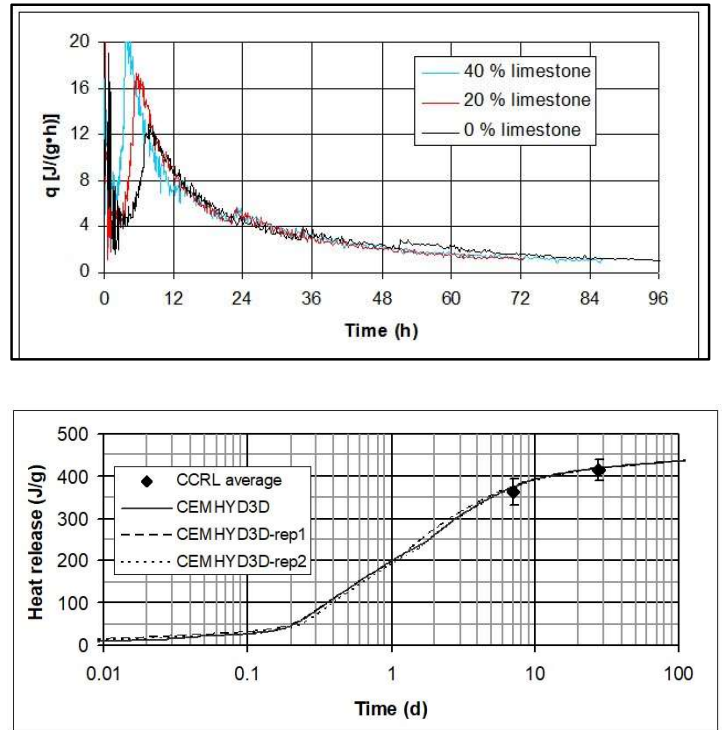

(b)

1 Figure 14: Published heat evolution of plain and limestone cements [20,14]

4

5

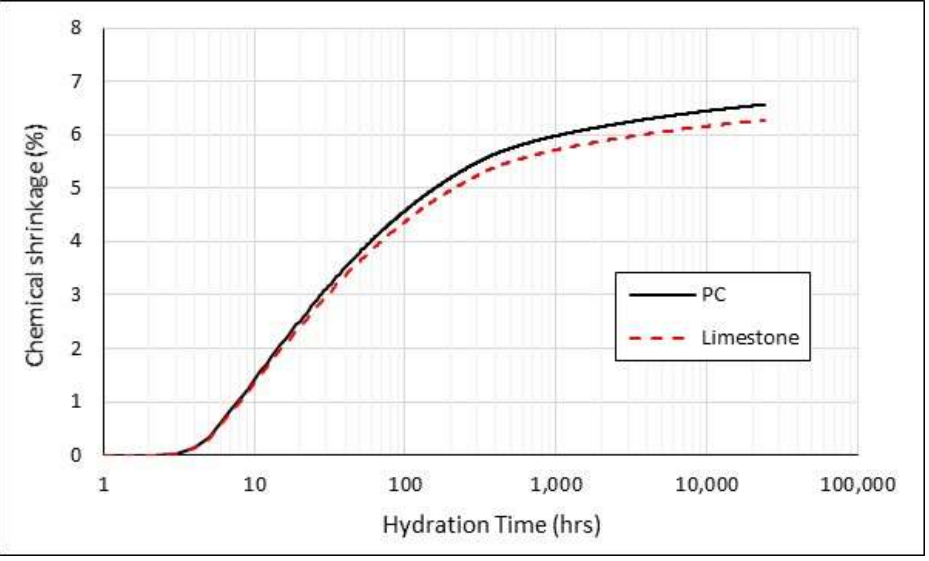

6 Figure 15: HYDCEM predicted chemical shrinkage. Solid line $=$ PC; dashed line $=$ Limestone 7 




(a)



(b)

1 Figure 16: Measured chemical shrinkage for various cements and w/c ratio from the literature [33]

2

3
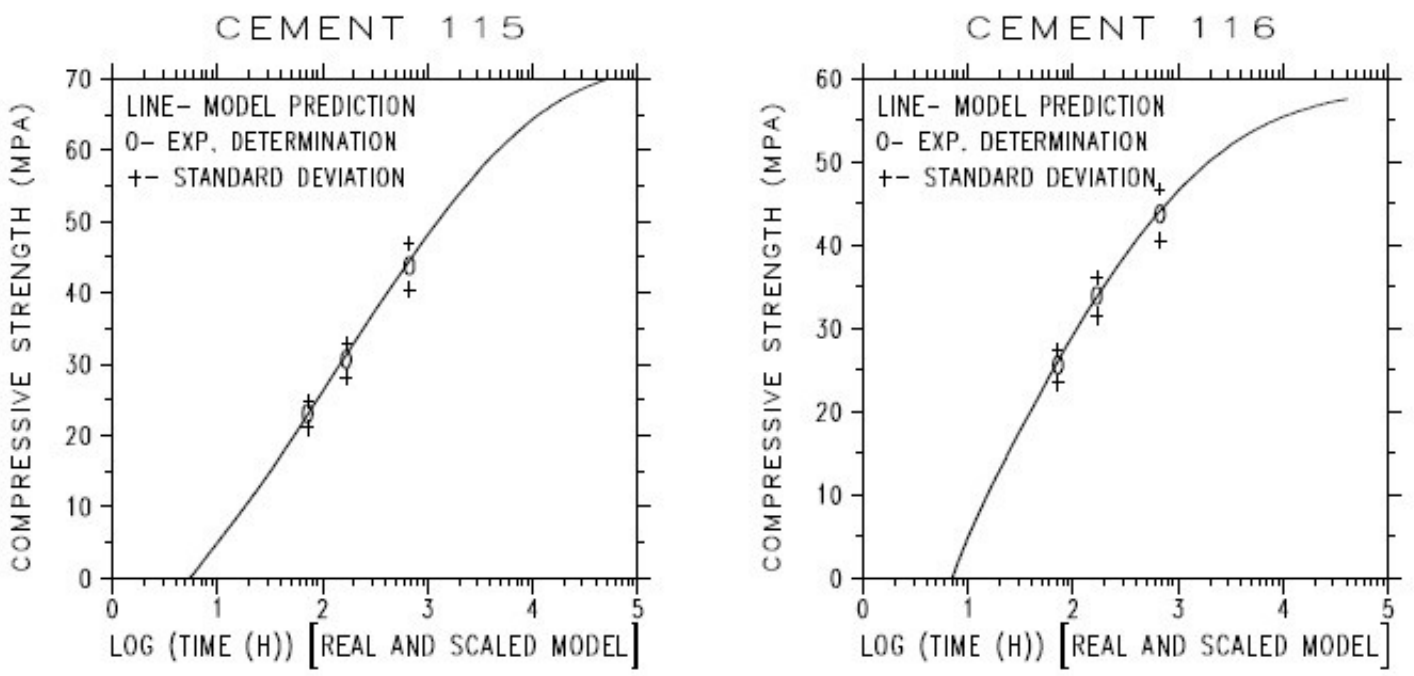

4

$5 \quad$ Figure 17: Predicted and measured compressive strengths for NIST Cements 115 and 116 [34]

6 


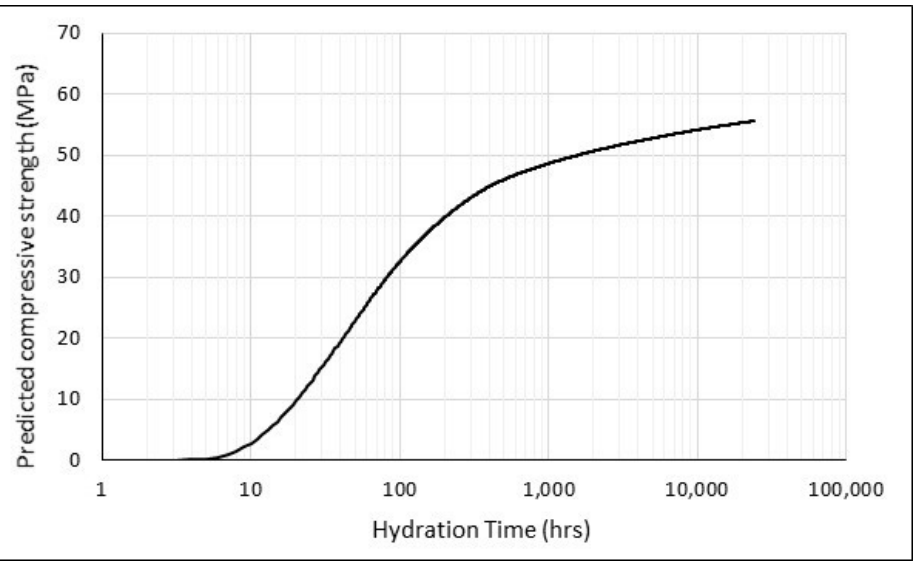

2 Figure 18: Predicted mortar compressive strength 3 


\section{LIST OF TABLES}

2

3 Table 1: Cement chemical analysis following [from 20] and phase proportions as calculated using

4 HYDCEM for the two cements

\begin{tabular}{|c|c|c|}
\hline & $\begin{array}{c}\text { PC } \\
(\mathrm{g} / 100 \\
\mathrm{g})\end{array}$ & $\begin{array}{c}\text { Limestone } \\
(\mathrm{g} / 100 \mathrm{~g})\end{array}$ \\
\hline $\mathrm{SiO}_{2}$ & 20.2 & 0.8 \\
\hline $\mathrm{Al}_{2} \mathrm{O}_{3}$ & 4.9 & 0.3 \\
\hline $\mathrm{Fe}_{2} \mathrm{O}_{3}$ & 3.2 & 0.3 \\
\hline $\mathrm{CaO}$ & 63.9 & 55 \\
\hline $\mathrm{MgO}$ & 1.8 & 1.8 \\
\hline $\mathrm{Na}_{2} \mathrm{O}$ & 0.42 & 0.01 \\
\hline $\mathrm{K}_{2} \mathrm{O}$ & 0.78 & 0.01 \\
\hline $\mathrm{CaO}$ free & 0.93 & 0.01 \\
\hline $\mathrm{CO}_{2}$ & 0.26 & 42.5 \\
\hline $\mathrm{SO}_{3}$ & 2.29 & 0.05 \\
\hline Soluble $\mathrm{Na}_{2} \mathrm{O}$ & 0.09 & 0 \\
\hline Soluble $\mathrm{K}_{2} \mathrm{O}$ & 0.72 & 0 \\
\hline $\mathrm{w} / \mathrm{c}$ ratio & \multicolumn{2}{|r|}{0.4} \\
\hline Temperature $\left({ }^{0} \mathrm{C}\right)$ & \multicolumn{2}{|r|}{20} \\
\hline Phase proportions & PC & $\mathbf{L S}$ \\
\hline $\mathrm{C}_{3} \mathrm{~S}$ & 64.02 & 60.60 \\
\hline $\mathrm{C}_{2} \mathrm{~S}$ & 9.61 & 9.63 \\
\hline $\mathrm{C}_{3} \mathrm{~A}$ & 7.57 & 7.24 \\
\hline $\mathrm{C}_{4} \mathrm{AF}$ & 9.74 & 9.33 \\
\hline
\end{tabular}

5

6 Table 2: Phase enthalpy values used in HYDCEM [14]

\begin{tabular}{|l|l|}
\hline Phase & Enthalpy $(\mathrm{J} / \mathrm{g})$ \\
\hline $\mathrm{C}_{3} \mathrm{~S}$ & 517 \\
\hline $\mathrm{C}_{2} \mathrm{~S}$ & 262 \\
\hline $\mathrm{C}_{3} \mathrm{~A}$ & 1144 \\
\hline $\mathrm{C}_{4} \mathrm{AF}$ & 725 \\
\hline
\end{tabular}

7 